\title{
Holistic but Customized Resources for a Course in Numerical Methods
}

This is an exact preprint of the paper "Holistic but Customized Resources for a Course in Numerical Methods”, by A.K. Kaw, N. Collier, M. Keteltas, J. Paul, G.H. Besterfield, in the journal - Computer Applications for Engineering Education, Vol. 11 (4), pp. 203-210, 2003 Copyright 2004 Wiley Periodicals, Inc.

\section{Autar Kaw (Corresponding Author), Professor, Mechanical Engineering Department Nathan Collier, Graduate Student, Mechanical Engineering Department Michael Keteltas, Undergraduate Student, Mechanical Engineering Department Jai Paul, Graduate Student, Mechanical Engineering Department Glen Besterfield, Associate Professor, Mechanical Engineering Department} University of South Florida, 4202 E Fowler Ave, Tampa, FL 33620-5350.

\begin{abstract}
$\underline{\text { Abstract }}$
Prototype web based resources have been developed for an undergraduate course in Numerical Methods. The web modules are holistic, that is they include pre-requisite information, real-life applications, presentations and notes, simulations, and selfassessment. The student interest and learning are maximized by providing customization of content based on a student's engineering major and computational system of choice.
\end{abstract}

\section{$\underline{\text { Keywords }}$}

Numerical methods, web enhanced courses, Mathcad, Maple, Matlab, Mathematica 


\section{$\underline{\text { Introduction }}$}

Below is one of the many conversations (The acts and the names of the characters are real! Resemblance to persons and incidents, past or present, are true and not coincidental) the first author has had with undergraduates using numerical methods and computational systems [1-4] to solve problems in engineering courses.

Peter: "Dr. Kaw, I am taking a course in Manufacturing. We need to find an efficient and smooth path that a robot could traverse to inspect holes at 10 specific locations on a 12"x12” square plate. I am using Maple [2] to fit a ninth order polynomial through the 10 points. But, when I plot the polynomial, it is oscillatory! It is a smooth path but by no means does it look efficient.”

Kaw: "As I recall, you took my course in Numerical Methods. What was that - one year ago?”

Peter: "Yes, your memory is sharp but my retention from that course - can we not talk about that!”

Kaw: "Come into my office. I wrote this program using Maple [2]. See this function, $f(x)=1 /\left(1+25 x^{2}\right)$. I am choosing 9 points equidistantly between -1 and 1 . Now look at

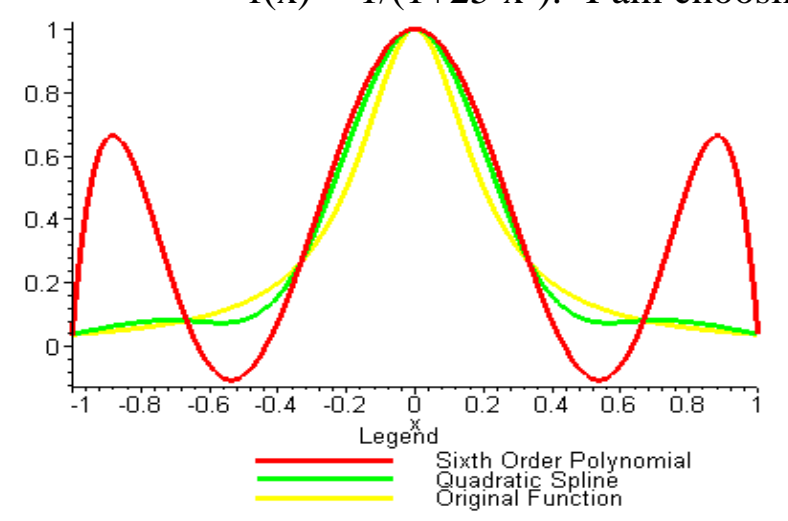

Figure 1: Higher Order Interpolation is a the eight order interpolating polynomial and the original function (See Figure 1). See the oscillations in the interpolating polynomial. In 1901, Runge [5] used this example function to show that higher order interpolation is a bad idea. One of the solutions to your problem is to use quadratic or cubic spline interpolation option in Maple. That will give you a smooth curve with no oscillations.”

Most experienced engineering faculty will attest to have had conversations similar to these with current and former students. In engineering courses, we want our students to gain a comprehensive and conceptual understanding of engineering principles and not have to struggle with the mathematical and numerical aspects of engineering problems. When it comes to applying numerical methods, why do our students in upper level engineering courses face problems like these [6,7]? The following are the main reasons. 
$\checkmark$ In many US public universities, under legislative pressure, graduation requirements for undergraduate engineering degrees have been reduced 8-10 credit hours to be comparable to liberal arts degrees. To accommodate these reductions, some have dropped the Numerical Methods course or reduced its credit hours. Others programs have bundled numerical methods in courses such as "Quantitative Methods" where students are also expected to learn linear algebra, programming language or computational system, and complex analysis.

$\checkmark$ With increasing use and popularity of computational systems [1-4], some curriculums rely too heavily on them rather than on a healthy balance with traditional numerical methods. In such cases, most students lack ability to interpret the results of a computational system.

$\checkmark$ Some curriculums introduce numerical methods as per need basis such as introducing simultaneous linear equations in Statics, eigenvalues/eigenvectors in Vibrations, and ordinary differential equations in Circuit Theory or Systems Modeling. Unless regulated carefully, the course content/depth of numerical methods in such course can vary substantially between instructors. In universities, such as those of the authors, such regulation is impossible. More than $50 \%$ of the upper-level engineering students at the University of South Florida (USF) are transfers from different community colleges.

$\checkmark \quad$ In universities with large nontraditional students population, such as those of the authors, many students take longer to complete their degrees and retention of course content diminishes dramatically over time. In a recent survey [8] conducted of all the students in the Numerical Methods course at USF, $42 \%$ took the pre-requisite course four or more semester prior to enrolling in the Numerical Methods course, 49\% work more than 20 hours/week, and 20\% anticipate to take more than seven years to finish their undergraduate degree. (The survey included 116 students of the Summer 2001, Summer 2002 and Spring 2003 classes of Numerical Methods at University of South Florida. Other notable results of the survey include: $15 \%$ are over the age of $26,17 \%$ are women and underrepresented minorities, $52 \%$ are transfer students from community colleges, and $21 \%$ are adults over thirty years old who are changing their career path) 
All the above reasons become all the more critical when $43 \%$ of the 5000 engineering professors surveyed [9] believe that students drop out of engineering because they have not mastered difficult mathematical skills.

\section{Objectives}

To address the above concerns as well as to enhance the quality of teaching and learning numerical methods, a prototype project [10] of holistic web-based modules for numerical methods has been developed (http://numericalmethods.eng.usf.edu). The project was funded by the National Science Foundation and includes topics of nonlinear equations and interpolation. The objectives of the prototype project were the following.

$\checkmark$ Develop holistic web-based modules that

o Provide a contextual background for the pre-requisite mathematical procedures.

o Motivate students to learn fundamentals and related concepts (pitfalls, errors and convergence) of numerical methods through real-life application examples and stories (such as provided in Act I) and by using combination of text and interactive graphical simulations.

o Allow self-assessment at every step of the learning process.

o Provide a resource for students not taking a formal course in Numerical Methods or using Numerical Methods in other courses.

$\checkmark$ Enhance learning and teaching of numerical methods by

o Providing customization of content based on engineering major and computational system.

o Offering convenience through anytime-anywhere web access.

o Presenting selection among wide variety of numerical techniques.

\section{$\underline{\text { Customization }}$}

Most universities currently use one of the following four computational systems in their engineering curriculum - Mathcad, Maple, Mathematica, or Matlab. Also, to teach and 
illustrate numerical methods, many departments of engineering use textbooks and examples geared toward their specific area or major. However, catering to all languages and all majors is not possible in a traditional printed textbook. Hence, on the home page of the website, a student/faculty is able to choose a customized track (See Figure 2) as described next.

Computational system - The user has a choice among the four most widely-used computational systems, namely, Maple, Mathcad, Mathematica, and Matlab. There are two main reasons for developing simulations using all the four computational systems.

1. For continuity, cost and pedagogy, a college may emphasize only one of these packages in their curriculum.

2. There is no additional cost involved if a university already has a site license to one of the four computational systems.

Engineering major - The user has a choice among seven majors - Chemical, Civil, Computer, Electrical, General, Industrial, and Mechanical. Specific examples used to illustrate numerical methods come from each of the areas. This choice is expected to hold the user's attention, as it closely relates to real-life problems of his or her interest. The "General” major choice is catered to students who

\footnotetext{
$\checkmark \quad$ have not declared a major, or

$\checkmark \quad$ have a specialized major such as Biomedical Engineering, or

$\checkmark \quad$ have a broad major such as Engineering Science, or

$\checkmark$ are science and mathematics majors.
}

\section{$\underline{\text { Holistic Content }}$}

Currently, there is no complete and comprehensive web package available for the Numerical Methods course. Most efforts [11-17] reported in the literature have involved the application of numerical methods software in other courses, or in applying a particular computer language or computational system to teach the diverse student learners enrolled in a numerical methods course. 
Examples of the use of a particular computer language or computational system in teaching numerical methods include occasional freely available simulations $[11,12]$, but this list is sparse. Several numerical methods textbooks $[13,14,15]$ include the use of a computational system (mostly Matlab or Mathematica); while other textbooks [16] use examples from specific engineering majors to introduce numerical methods. This emphasis on a particular major or computational system in a book is beneficial only if it suits your particular needs. Unfortunately, it alienates instructors who may otherwise like the book content, but are using a different computational system or are teaching a different major.

Still other books [5] use generic examples to illustrate numerical methods and then show the use of several computational systems. The use of generic examples reaches a wider audience, but it does not pique the interest of students as much as real-life problems.

The above is not to criticize such books but it demonstrates that what is done in this project can only be done through the web. That is, allow faculty and students to concentrate on the fundamentals of the course and at the same time customize it by the choice of application examples based on designated engineering major and specific computational system. To accomplish what is being done with the web based resources in this paper in a textbook would require an author to write 28 textbooks (for seven majors and four computational systems). Moreover, such texts would still lack the availability of the all-important active learning simulations of numerical methods and their related concepts.

Once the user selects a track based on one of the seven engineering majors and one of the four computational systems, web-based modules include the following topics of nonlinear equations and interpolation (Figure 3).

Background Review: In this section, the theory of the mathematical procedure is introduced and discussed based on the ideas introduced in the previously completed mathematics courses. Examples are provided and exact methods are discussed. This lays a foundation for the need for numerical methods, as most problems do not have exact solutions. Historical anecdotes such as those of Galois’ pessimistic view of solving nonlinear equations are included.

Modeling: Students introduced to numerical methods with generic functions and data without direct relation to physical applications easily lose interest in the course. For each 
mathematical procedure, models (Figure 4) of seven physical examples (corresponding to engineering major) are developed to show the need for finding solutions numerically. The examples chosen then become a common theme for developing and comparing different numerical methods.

Numerical Methods and Associated Concepts: The development of commonly used numerical methods is shown for each mathematical procedure. Each numerical method combines both text and interactive simulations. For the roots of nonlinear equations, algorithms are developed for the bisection method, Newton-Raphson method, and secant method. For interpolation, algorithms are developed for the direct method, Newton's divided difference polynomial method, Langrangian interpolation, and the spline method. Using anecdotal conversations such as illustrated in Acts I \& II, advantages and pitfalls are discussed, and round off and truncation errors, and convergence of each numerical technique are also simulated. For example, to show extrapolation is dangerous, we include the prediction of the stock market indexes; to show higher order interpolation is a bad idea, we use Runge's function (Figure 1); to show how spline and polynomial interpolation differ, we use calculating the length of the path of a robot as an example (Figure 5).

Self-Assessment: At the end of each section, the student answers a series of well constructed multiple-choice questions. All multiple-choice options are chosen such that they address common mistakes and myths. The questions are distributed over all levels of objectives of Bloom's taxonomy [17].

Format of Content: All project contents are available in several formats. Text documents are available in three formats - HTML for general format, PDF for printer friendly version, and Word for customization. Simulations are offered in four computational systems - Mathcad, Maple, Mathematica, and Matlab. These simulations can be modified by students to run their own examples. Self-assessment tests are accessible in HTML format for immediate feedback.

\section{Use as a Teaching Tool}

Many universities currently have multimedia classrooms that are equipped with student computers and instructor stations, internet connections and multimedia projectors. Thus during class sessions, instructors will be able to go to the website and bring the workings of a numerical technique to life. 
Questions commonly asked by students in a Numerical Methods course often require the instructor to conduct numerical experiment in class that are time prohibitive during the lecture and thus need to carry over to the next class period. The project contents not only support the spontaneity of answering many classroom questions but also the active engagement of students to run their own simulations in class or at home.

Of comparable importance, in engineering courses where the knowledge of numerical methods or application of a computational system needs to be reviewed or introduced, the website can be used as a reference. Since self-learning and self-assessment of the fundamentals of numerical methods are two of the main features of the project, the instructor can direct majority of their instructional efforts to teaching engineering fundamentals.

\section{$\underline{\text { Resources }}$}

The complete resources of this paper are given at http://numericalmethods.eng.usf.edu.

\section{Conclusions}

Prototype web based resources have been developed at the University of South Florida for an undergraduate course in Numerical Methods (http://numericalmethods.eng.usf.edu). The web modules are holistic in nature. They provide a contextual background and history of numerical methods, and further motivate students to learn fundamentals through real life applications, presentations, textbook style notes, and simulations of methods including convergence and pitfalls, and selfassessment.

The student interest and learning are maximized by providing customization of content based on 28 tracks based on seven engineering majors (Chemical, Civil, Computer, General, Industrial, Electrical and Mechanical Engineering) and four computational systems (Maple, Mathcad, Mathematica and Matlab). The motivation for having 28 tracks is based on teaching students by what major they are enrolled or interested in, and what computational system is available or taught to them.

The resources are offered conveniently through anytime-anywhere web access throughout one's degree program and hence broadly impact students and faculty of a Numerical Methods course as well as of engineering courses where numerical methods and computational systems are used. It is free of charge to anyone in the world. To 
quote the open courseware (OCW) [18] initiative at MIT, our attempt is "having open dissemination of educational materials, philosophy, and modes of thought, that will help lead to fundamental changes in the way colleges and universities utilize the Web as a vehicle for education."

\section{Acknowledgements}

This material is based upon work supported by the National Science Foundation under Grant No. 0126793, and the Research for Undergraduate Program in the College of Engineering at the University of South Florida. Any opinions, findings, and conclusions or recommendations expressed in this material are those of the author(s) and do not necessarily reflect the views of the National Science Foundation. We also want to thank Paul Sanders and Ginger Williams who also contributed to this project.

\section{References}

1. MATHCAD2001, The Industry Solution for Applying Mathematics. See http://www.mathcad.com.

2. Maple 6.0, Advancing Mathematics. See http://www.maplesoft.com.

3. MATHEMATICA 4.1, The Way the World Calculates. See http://www.wolfram.com/.

4. Matlab 6: Increasing The Scope and Productivity of Engineering Science. See http://www.mathworks.com/.

5. S.C. Chapra and R.C. Canale, A Numerical Methods for Engineers with Programming and Software Applications, WCB McGraw Hill, New York, 1996.

6. J. Esperson, “On the Runge Example”, American Mathematical Monthly, Vol. 94, pp. 329-341, 1987.

7. G.E. Forsythe, "Pitfalls in Computation, or Why a Math Book Isn't Enough", American Mathematical Monthly, Vol. 77, pp. 931-956, 1970.

8. Student Survey of Numerical Methods - Summer 2001. See: http://www.eng.usf.edu/ kaw/numericalmethods/surveysummer2001.pdf . 
9. “Students Aren’t Prepared for Engineering, Profs Say”, USA Today, February 19, 2001.

10. HNMI - Holistic Numerical Methods Institute: Committed to Bringing Customized Numerical Methods Holistically to Undergraduates. See http://numericalmethods.eng.usf.edu.

11. M.C. Bartholomew-Biggs, "Software to Support Numerical Analysis Teaching”, International Journal of Mathematical Education in Science and Technology, Vol. 31, pp. 857-867, 2000.

12. J.H. Mathews, "Using MATLAB as a Programming Language for Numerical Analysis”, International Journal of Mathematical Education in Science and Technology, Vol. 25, pp. 481-490, 1994.

13. L.V. Fausett, Applied Numerical Analysis using Matlab, Prentice Hall, New York, 1999.

14. G. Recktenwald, Numerical Methods with Matlab, Prentice Hall, New York, 2000.

15. R.J. Schilling and S.L.Harris, Applied Numerical Methods for Engineers Using MATLAB and C, Brooks/Cole, Pacific Grove, CA, 2000.

16. A. Constantinides and N. Mostoufi, Numerical Methods for Chemical Engineers with MATLAB Applications, Prentice Hall, New York, 1999.

17. B.S. Bloom, Taxonomy of Educational Objectives. Handbook I: Cognitive Domain, David McKay Co., 1956.

18. MIT OpenCourseWare - 2003. See: $\underline{\text { http://ocw.mit.edu/ }}$ 


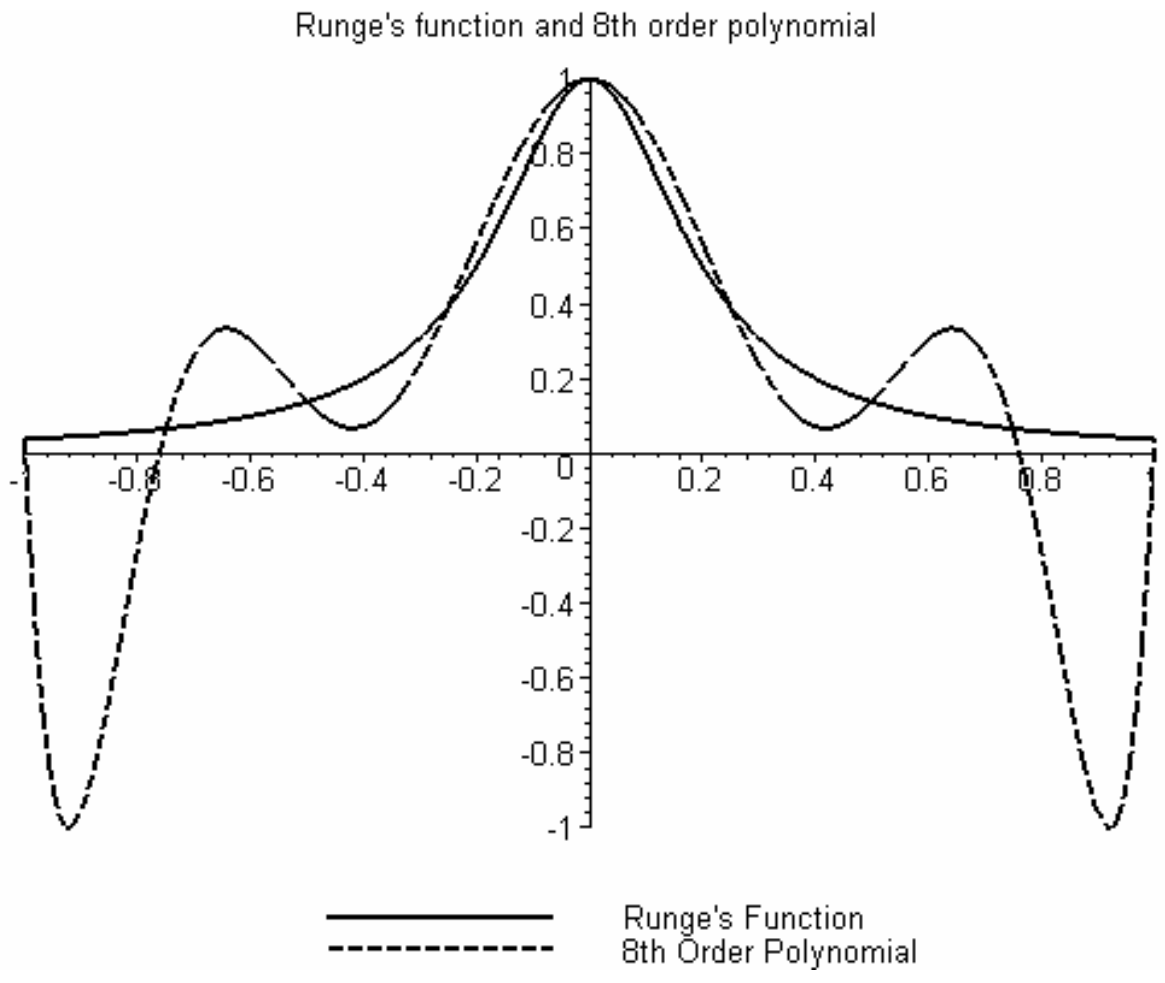

Figure 1: Runge's function used to show that higher order interpolation is a bad idea (The above plot was generated using Maple [2]). 
- Edit View Favorites Iools Help

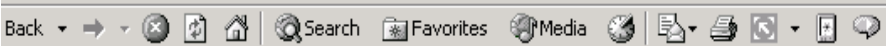

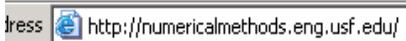

HNMT

holistic Numerical Methods institute (HNMI)

Committed to Bringing Customized Numerical Methods Holistically to Undergraduates

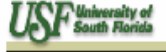

http://numericalmethods, eng.usf.edu

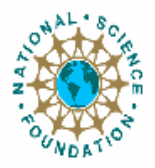

HOME | RESOURCES | MATRIX ALGEBRA BOOK | SITE INDEX | DISSEMINATION | PUBLICATIONS | SEARCH | FAQS| CONTACT

\begin{tabular}{l|l|l|}
\cline { 2 - 3 } QUICK LINK & Choose a topic \\
OTHER QUICK & Choose a topic \\
LINKS & OhO Choose an engineering major G \\
\hline Oh no! Nothing happens when I click the GO button. If that happens, choose the exact same resources by going to text only \\
links. (Check all resources regular links or text links)
\end{tabular}

Figure 2: Customized track based on engineering major and language of choice 
Holistic but Customized Resources for a Course in Numerical Methods 13 
Holistic but Customized Resources for a Course in Numerical Methods 14 
Holistic but Customized Resources for a Course in Numerical Methods 15 
Holistic but Customized Resources for a Course in Numerical Methods 16 
Holistic but Customized Resources for a Course in Numerical Methods 17 
Holistic but Customized Resources for a Course in Numerical Methods 18 


\section{LANGUAGE MATHCAD}

\section{INTERPOLATION}

\section{MAJOR GENERAL}

\section{Background}

What is interpolation? [PDF] [DOC]

History of interpolation [PDF] [DOC]

Test your knowledge on background of interpolation [HTML] [PDF] [DOC]

Physical Problem

The upward velocity of a rocket is given as a function of time. To find the velocity of the rocket at some other time, the problem requires interpolation. [ $\underline{\mathrm{PDF}}][\underline{\mathrm{DOC}}]$

Numerical Method

Direct method:

How does the direct method work? [PDF] [DOC]

A Power point presentation [PDF] [PPT]

Simulations of the method [PDF] [MCD]

Anecdotes and special topics [GO]

Test your knowledge of the method [HTML] [PDF] [DOC]

Newton's divided difference polynomial method:

How does the Newton's divided difference polynomial method work? [PDF] [DOC]

A Power point presentation [PDF] [PPT]

Simulations of the method [PDF] [MCD]

Anecdotes and special topics [ㅇ] 
Test your knowledge of the method [HTML] [PDF] [DOC]

Lagrangian method:

How does the Lagrangian method work? [PDF] [DOC]

A Power point presentation [ $\underline{\mathrm{PDF}}][\underline{\mathrm{PPT}}]$

Simulations of the method [PDF] [MCD]

Anecdotes and special topics [므]

Test your knowledge of the method [HTML] [PDF] [DOC]

Spline Method:

How does the spline method work? $[\underline{\mathrm{PDF}}][\underline{\mathrm{DOC}}]$

A Power point presentation [PDF] [PPT]

Simulations of the method [PDF] [MCD]

Anecdotes and special topics [GO]

Test your knowledge of the method [HTML] [PDF] [DOC]

$\underline{\text { Anecdotes }}$

The lurking dangers of extrapolation! [ $\underline{\mathrm{PDF}}[\underline{\mathrm{DOC}}] \underline{\mathrm{MCD}}]$

Why is higher order interpolation is a bad idea? [PDF] [DOC] [MCD]

Comparison of spline and polynomial interpolation. [DF] [DOC] [MCD]

How choice of points of interpolation affects approximations! [PDF] [DOC] [MCD]

How splines can help in developing a shorter path for a robot! [PDF] [DOC] [MCD]

Runge [HTML] [PDF] [DOC]

Newton [HTML] [PDF] [DOC]

Lagrange [HTML] [PDF] [DOC] 
Figure 3. Sample web-based resources for interpolation for General Engineering and Mathcad track. 


\section{Physical Probl ems (Non-Linear Equations)}

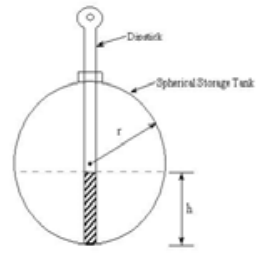

Chemical Engineering A scale to measure oil in a tank

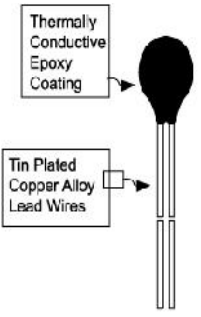

Electrical Engineering Calibrating a thermistor.

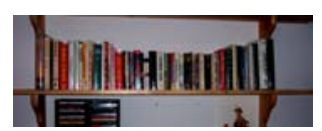

Civil Engineering

Sagging bookshelves no more!

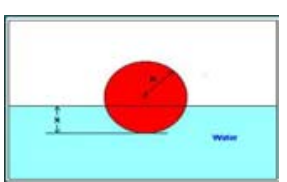

General Engineering How much of the float is submerged?

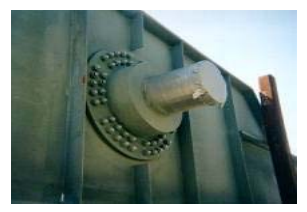

Mechanical Engineering How much to cool down to shrink fit?

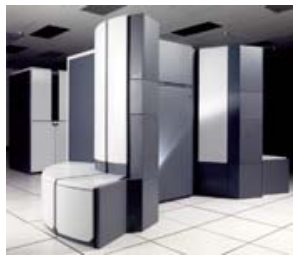

Computer Engineering Divide unit missing in a supercomputer?

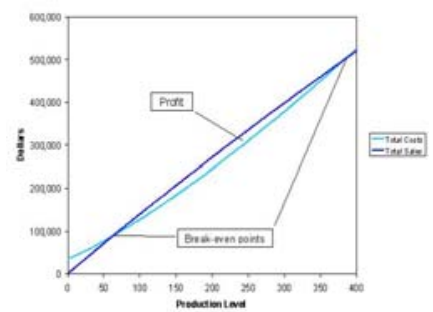

Industrial Engineering Mom and Pop shop wants to break even.

Figure 4. Physical problems from different engineering majors to illustrate need for numerical methods. 


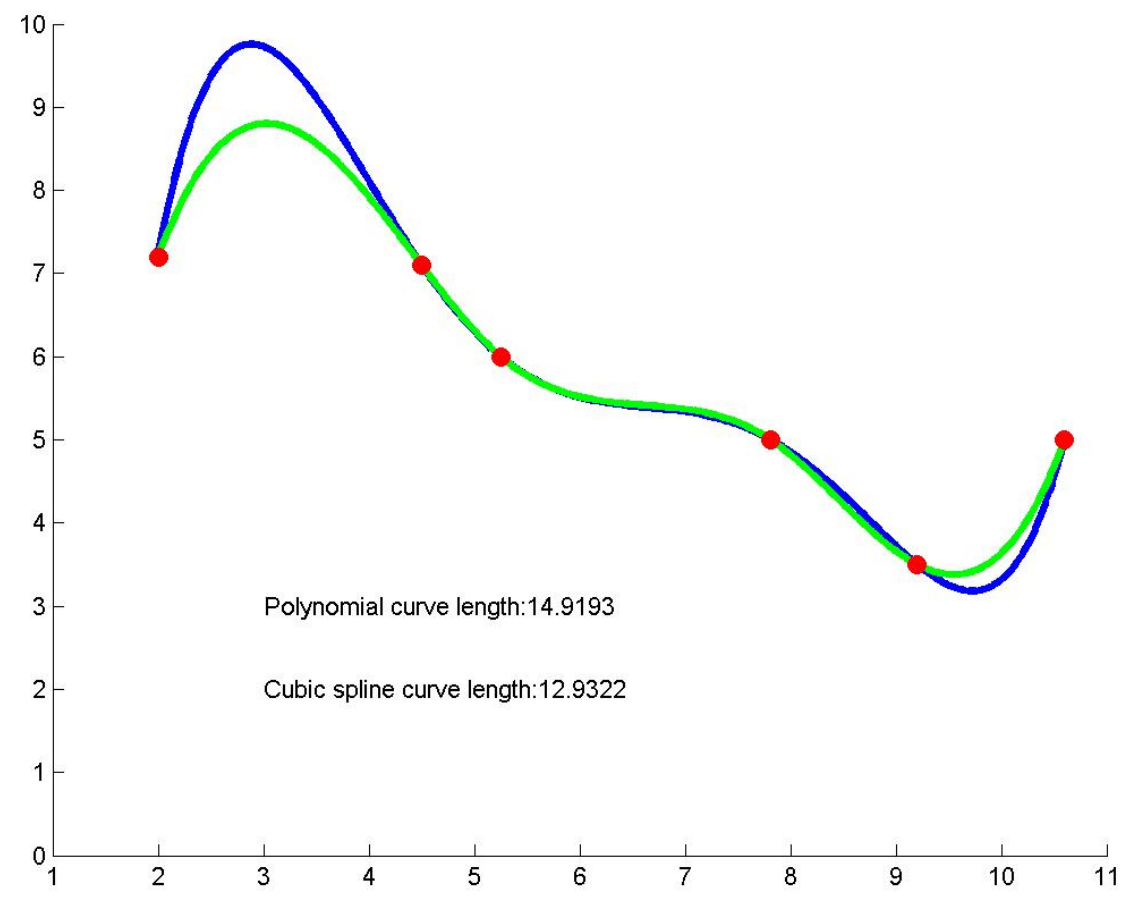

Figure 5. Anecdotal example of finding the length of the path traversed by a robot using polynomial and spline interpolation (The above plot was generated via Mathematica [3]). 


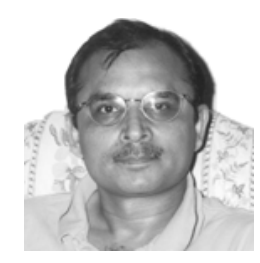

Autar K Kaw is a Professor of Mechanical Engineering and Jerome Krivanek Distinguished Teacher at the University of South Florida. He has authored the textbook - Mechanics of Composite Materials, CRC-LLC Press. His current scholarly interests include development of instructional technologies, integrating research in classroom, thermal stresses, computational mechanics, and composite materials. He is the recipient of the 2003 ASEE Archie Higdon Distinguished Mechanics Educator Award.

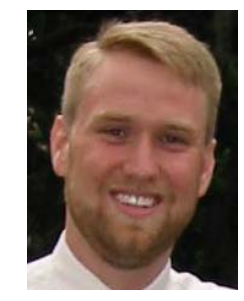

Nathan Collier is a graduate student in the Mechanical Engineering Department at the University of South Florida. He has worked on the Holistic Numerical Methods Website by developing the simulations in four different computational systems. He is skilled in scientific computer programming, and has taught an introductory course in Visual Basic for three semesters. His thesis work is on optimizing trunnion-hub assembly procedures for bascule bridges.

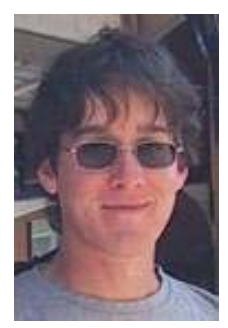

Michael Keteltas is an undergraduate in the Mechanical Engineering Department at USF. For the web-based resources described in this paper, he compiled historical anecdotes, example stories, and developed a database for the dissemination of the website. 


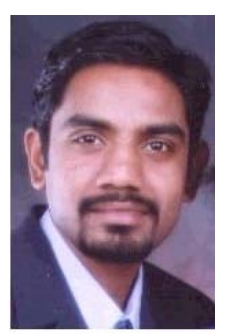

Jai Paul is a graduate student in the Mechanical Engineering Department at the University of South Florida. He received his Bachelor's degree with first class and distinction from Bangalore University, India. For the website described in this paper, he developed simulations, PowerPoint presentations, and was a teaching assistant for the Numerical Methods course.

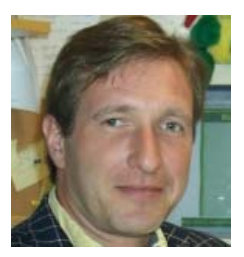

Glen H Besterfield is an Associate Professor of Mechanical Engineering at the University of South Florida. He has co-authored the textbook entitled Total Quality Management. His main scholarly interests include, but are not limited to, history of technology, rehabilitation engineering, bascule bridges, assessment techniques, probabilistic mechanics, computational mechanics, finite element methods, and total quality management. 